\title{
Electrostatic power generation using carbon-activated cotton thread on textile
}

\author{
Baek Hyun Kim, Benjamin S Barnhart and Jae W Kwon*
}

\begin{abstract}
This paper describes a novel thread-shaped power generator which can be incorporated into cloth. A carbon-activated cotton thread is utilized for harvesting electrostatic energy from environment using contact and friction electrifications. A core of cotton thread was treated with carbon black nano particles to provide conductivity, and then encapsulated with a thin layer of polydimethylsiloxane for stability and protection. Electrostatic charges have been collected from carbon-activated threads stitched on pieces of textiles by repeated rubbing and tapping with a ploytetrafluoethylene sheet. An average open-circuit voltage of approximately $-60.9 \mathrm{~V}$ has been generated from the thread-shaped generator with rubbing mode.
\end{abstract}

Keywords: Electrification; Cotton thread; Textile

\section{Introduction}

In recent years, there has been rapid growth in the diversity and application of small electronics, as evidenced by the increasing global prevalence of portable systems. Remarkable advancements of micro/nanotechnologies have resulted in the emergence of new applications including novel wearable electronics, the importance of which is on the rise [1-8]. As device size is minimized for certain applications, the development of compatible small power sources and connections has become more important than ever. To this end, the challenge is to integrate a power source for the wearable electronic devices. Most wearable electronics have been dominated by small devices being conspicuously mounted or adhered onto textiles, and are inconvenient to use. Here, we introduce a thread-based power harvester which can be inconspicuously integrated in textiles and supply power for small wearable electronics. The future will see many devices embedded into fabric itself, while maintaining the aesthetic value of fabrics and garments.

Currently, one of the most common power sources for mobile electronics is the lithium-ion battery, but it is not appropriate for wearable electronics because of the potential fire hazard of lithium in air, in addition to the large size and heavy weight. Another drawback is the requirement for frequent recharging. Moreover, to avoid problems

\footnotetext{
* Correspondence: kwonj@missouri.edu

Department of Electrical and Computer Engineering, 349 Engineering Building West, University of Missouri, Columbia, MO 65211, USA
}

described above, various alternative methods of harvesting power from solar [9], wind [10], mechanical vibration [11], etc. have been considered, but size and weight are not easily reduced in order to be compatible with wearable electronics. Many energy conversion mechanisms require certain devices and materials which cannot be miniaturized to be unnoticeably hidden in textiles. However, we believe that especially, electrostatic energy generation seems very useful if the size of the harvester can be miniaturized. Electrostatic discharge from clothes is commonly seen because electrostatic energy can easily be generated by body motions. In general, electrostatic charge generation can be classified into contact electrification (charging by repeated contact and separation of two different surfaces) and frictional electrification (charging by dynamic rubbing of two surfaces) [12]. Compared to frictional electrification, contact electrification is relatively easy to analyze since there is no concern about the rubbing rate, temperature, and contact area on the static charge generation.

Here, we demonstrate a light and flexible thread-based power harvester, which can simply be woven into textiles. The contact and friction electrifications between a harvester integrated textile and a dissimilar material can provide enough output power to energize various wearable electronics. Furthermore, this thread-based electrostatic power generator is quite attractive because routine maintenance for battery operated devices may not be needed any more. 


\section{Findings}

Among the fabrics used for textile and apparel manufacture, cotton (natural cellulose) is the most commonly used material due to its processing simplicity, cost effectiveness, mechanical properties and overall comfort. In addition, various methods of treating cotton without losing cotton's unique set of physical properties have been broadly studied [13-22]. Thus, we used cotton as a base substrate material for a thread-based wearable power harvester and embedded carbon black nano particles within cotton threads for enhancing electrical conductive properties as depicted in Figure 1a. Carbon nanotubes (CNTs) are often considered as good conductive materials but very expensive [23]. Instead, the carbonactivated thread (CAT) power harvester can be easily and cost-effectively produced with normal cotton materials imbued with carbon black nano particles. In addition, we employed polydimethylsiloxane (PDMS) to enhance the stability of carbon black nano particles in the thread structure while experiencing mild but continuous mechanical forces and friction generated by rubbing and contacting. A thin layer of carbon black nano particles mixed with PDMS preserves the flexibility, elasticity and conductivity of the textile threads to a great extent, which makes them ideal for application in electronic textiles. When this mixture was applied on cotton thread, the resistance was 255.3 $\mathrm{k} \Omega$ over a distance of $3 \mathrm{~cm}$. To build the CAT structure using normal cotton threads with a diameter of approximately $100 \mu \mathrm{m}$ (measured by a caliper), we

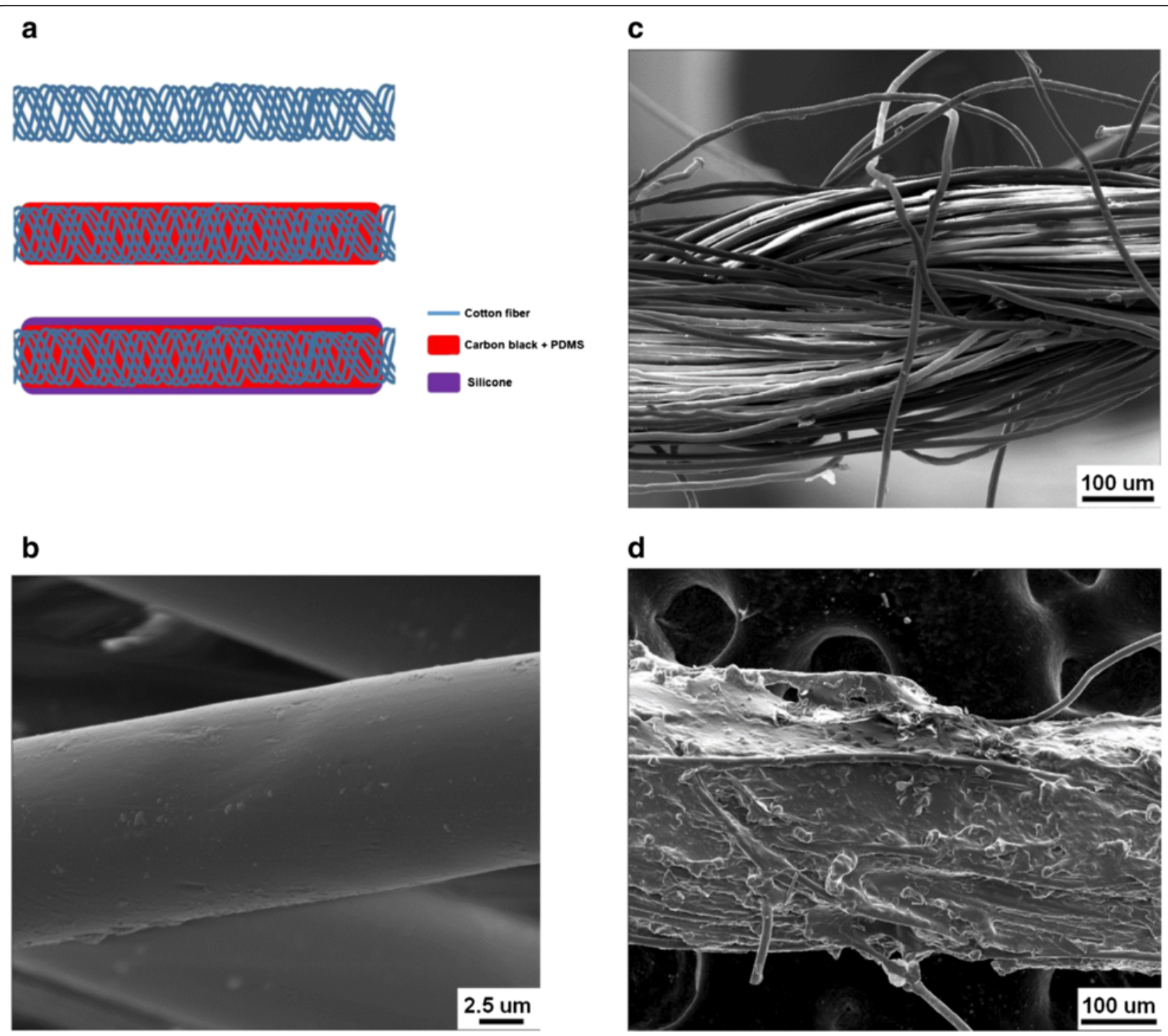

Figure 1 Carbon-activated cotton thread. (a) Schematic fabrication diagrams of carbon-activated cotton thread. SEM images of (b) a single cotton fiber (c) cotton thread consists of multiple cotton fibers and (d) finished carbon activated cotton thread. 
have employed simple coating techniques. The cotton threads were sequentially cleaned with acetone, methanol, and de-ionized water several times. Then, the cotton threads were soaked in a mixture of PDMS (MG chemicals, Canada) and carbon black powder with a weight ratio of $4: 1$ to become conductive. The resistance of the conductive cotton thread was measured to be approximately $85.1 \mathrm{k} \Omega / \mathrm{cm}$. In the final step, a mixture of ethyltriacetoxysilane and methyltriacetoxysilane was applied on the thread several times and air-dried at room temperature. There are several reasons that ethyltriacetoxysilane and methyltriacetoxysilane are used on the threads. First, carbon black particles used in this experiment easily become detached and are lost without a protection layer, and this causes loss in the total electrical conductivity of CAT. To maintain conductivity, we employed these two materials. After drying these two materials in ambient conditions, their hardness can also protect CAT from mechanical damage. Another reason for use of ethyltriacetoxysilane and methyltriacetoxysilane is to increase generation of electric power between carbon activated cotton thread and Polydimethylsiloxane (PTFE) by electrostatic generation. Because cotton has a neutral charge state, the generated charges could be reduced in cotton and the output performance of CAT would be dramatically degraded. Figure 1 also shows scanning electron microscope (SEM) images of the CAT power harvester built on cotton threat. Normal cotton thread consists of multiple fibers, where a single fiber has an average diameter of $12.07 \mu \mathrm{m}$, estimated by the SEM image in Figure 1b. Moreover, the diameters of normal cotton thread and CAT are very similar, $372.45 \mu \mathrm{m}$ and $369.57 \mu \mathrm{m}$, respectively. Normal cotton thread has large empty spaces between the fibers (Figure 1c) which are filled up with the mixture of carbon black nano particles and PDMS (Figure 1d).

Then, CAT power harvesters were stitched on thin and thick cloth samples for testing as shown in Figure $2 \mathrm{a}$ and $\mathrm{b}$, respectively. We have used cotton textiles and the thick cotton textile has a fluffier surface compared to the thin textile surface. Power outputs from each cloth were characterized by tapping and sweeping the surface with a PTFE sheet. For easy handling and testing with the PTFE sheet, we have used a large cylindrical plastic tube wrapped with a PTFE sheet (12 cm long, $5 \mathrm{~cm}$ wide, and $70 \mu \mathrm{m}$ thick) as illustrated in Figure 2c. The applied sweeping/tapping frequency was approximately $2 \sim 4 \mathrm{~Hz}$. Figure 3 shows the outputs of time-dependent open-circuit

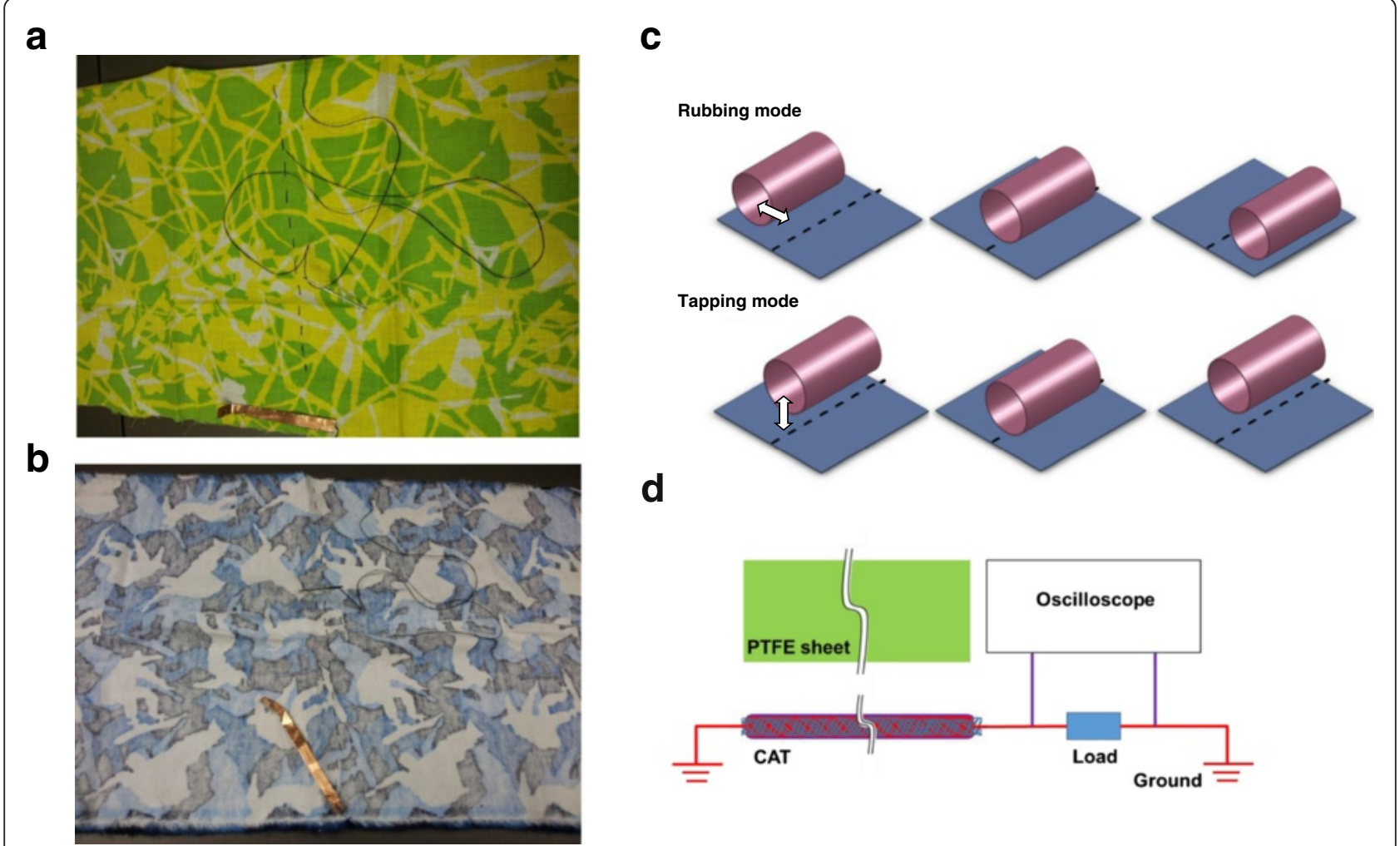

Figure 2 Assembled carbon-activated thread (CAT) harvester and power generation testing modes. Photographs of CAT harvesters stitched on (a) thin (less fuzz fibers) and (b) thick (more fuzz fibers) cotton textiles with a simple line pattern. Needles with black cotton CAT harvesters are presented in the middle of textiles. (c) Illustration of rubbing and tapping modes of the CAT harvester stitched on a textile. (d) Schematic drawing of testing setup of CAT harvester. 

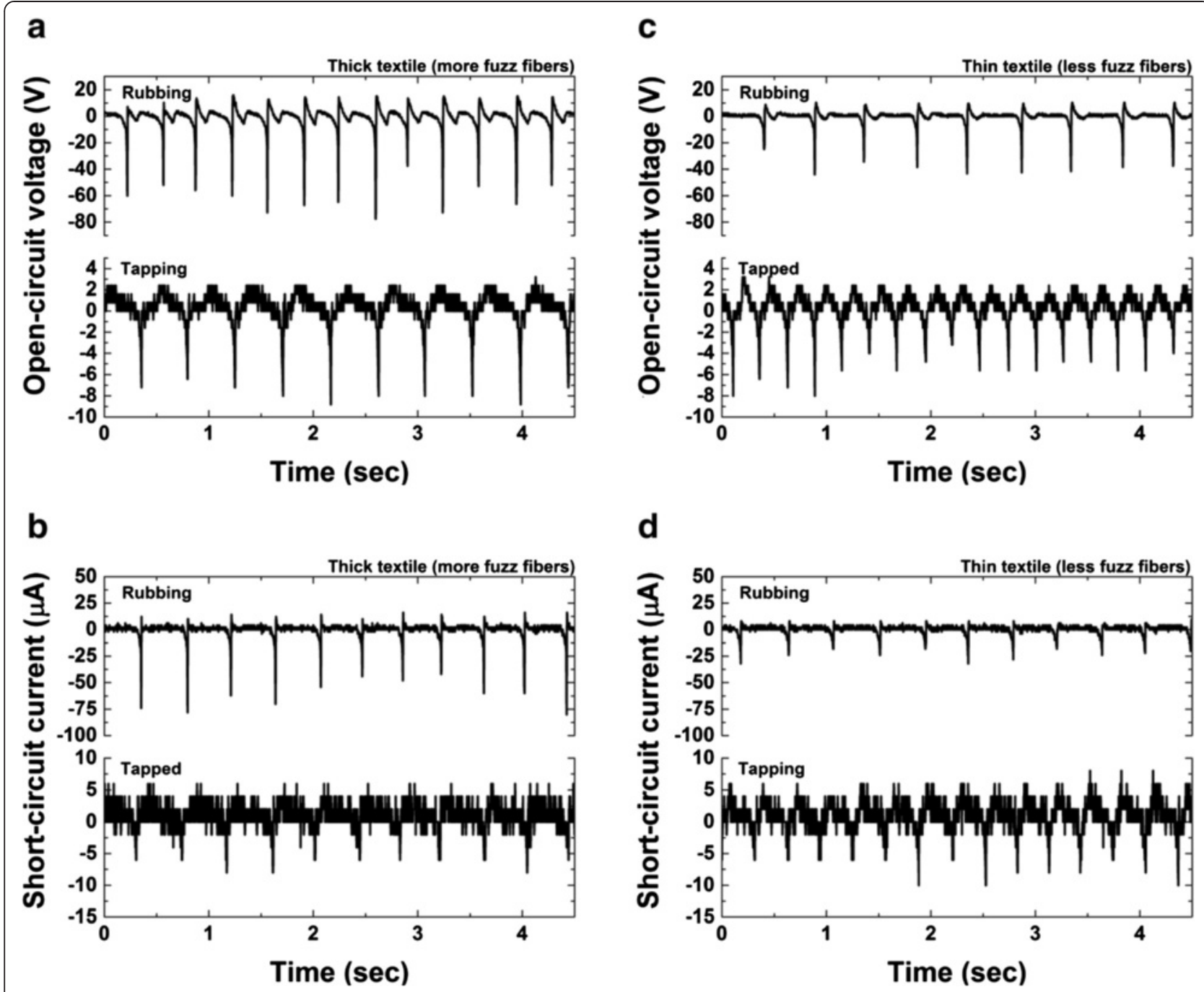

Figure 3 Output power characteristics of CAT harvesters. Output voltages and currents as a function of time when a PTFE sheet was rubbed and tapped with each CAT harvester stitched on a thick textile ( $\mathbf{a}$ and $\mathbf{b})$ and a thin textile (c and $\mathbf{d}$ ). The distace between CAT and PTFE sheet was about $15 \mathrm{~cm}$.

voltages and short-circuit currents that occurred when the CAT harvester was rubbed or tapped with PTFE. The CAT attracts electrons while in contact with PTFE. The rubbing mode on the thick cotton textile $(480 \mu \mathrm{m})$ has an average open-circuit voltage of approximately $-60.9 \mathrm{~V}$, while the tapping mode has an average open-circuit voltage of $-7.76 \mathrm{~V}$, as shown in Figure 3a. The thick cotton textile with rubbing mode shows a short-circuit current of $-61.08 \mu \mathrm{A}$, while the tapping mode has an average short-circuit current of $-6.54 \mu \mathrm{A}$, as shown by Figure $3 \mathrm{~b}$. For the thin cotton textile $(240 \mu \mathrm{m})$, however, the CAT with rubbing mode has an average opencircuit voltage of $-38.3 \mathrm{~V}$ and the tapping mode has an open-circuit voltage of $-5.55 \mathrm{~V}$, while the average short-circuit current for rubbing mode is $-23.63 \mu \mathrm{A}$, and the short-circuit current for tapping mode is
$-7.43 \mu \mathrm{A}$ as shown respectively in Figure $3 \mathrm{c}$ and $\mathrm{d}$. Results are summarized in Table 1 . The rubbing mode increases both open-circuit voltage and short-circuit current by 7.85 and 9.34 times, respectively, compared to the tapping mode when a thick cotton textile is used. On the other hand, when the thin cotton textile

Table 1 Summary of open-circuit voltages and short-circuit currents measured in rubbing and tapping modes

\begin{tabular}{lll}
\hline & $\begin{array}{l}\text { Thin cotton } \\
\text { textile }\end{array}$ & $\begin{array}{l}\text { Thick cotton } \\
\text { textile }\end{array}$ \\
\hline Open-circuit voltage in rubbing mode & $-38.3 \mathrm{~V}$ & $-60.9 \mathrm{~V}$ \\
Short-circuit current in rubbing mode & $-23.63 \mu \mathrm{A}$ & $-61.08 \mu \mathrm{A}$ \\
Open-circuit voltage in tapping mode & $-5.55 \mathrm{~V}$ & $-7.76 \mathrm{~V}$ \\
Short-circuit current in tapping mode & $-7.43 \mu \mathrm{A}$ & $-6.54 \mu \mathrm{A}$ \\
\hline
\end{tabular}


is used, the rubbing mode shows higher open-circuit voltage and short-circuit current by 6.9 and 3.18 times, respectively, compared to the tapping mode. Furthermore, the CAT harvester on the thick cotton textile increased open-circuit voltage and short-circuit current by $59 \%$ and $158.5 \%$ compared to that on the thin cotton textile for rubbing mode. This is because more fuzz fibers on the thick textile surface contributed to increase more charge buildup on the PTFE surface. However, in tapping mode, results from both textiles are almost same because the area that PTFE touches is very much limited without much interaction with fuzz fibers. We have also confirmed that the conductivity of CAT was maintained and the output performance was not degraded after many runs. Then, the CAT harvester was tested with a load of $100 \mathrm{M} \Omega$ and 10 yellow LEDs connected in parallel. When the CAT on the cotton textile was rubbed by PTFE, all the LEDs lighted up very brightly as shown in Figure 4 .

Conductive materials have significant electron mobility and consequently always maintain an electrical equilibrium. Although in nonconductive materials such as PTFE and PDMS, the low mobility of electrons does not provide for rapid recombination of charge imbalance. If contacted or rubbed, a dielectric may either give up electrons or capture free electrons. In general, PTFE accepts free electrons and becomes negatively charged by nature of the outer valence orbit [24]. While the PTFE sheet is rubbed with the cotton textile, the negative charges are accumulated on the surface of PTFE sheet due to the electron affinity difference between PTFE and cotton. When PTFE sheet rubs on CAT, those accumulated negative charges attract positive charges and try to rapidly eliminate the imbalance by recombination of the opposite charges. Since rubbing or repeated contact produces a large electric field gradient in nonconductive materials, there is a rapid release of electrons when discharge occurs [25]. For tapping mode, however, the PTFE sheet has little chance to contact with the cotton textile and the charges could not accumulate much before making contact with CAT.

In general, a material with the stronger affinity for negative charge attracts electrons. PTFE has a higher negative charge affinity $\left(-190 \mathrm{nC} \mathrm{J}^{-1}\right)$ than that of PDMS $\left(-72 \mathrm{nC} \mathrm{J}^{-1}\right)$. We have investigated electric field properties between the CAT harvester and a PTFE sheet with finite element analysis software (COMSOL multiphysics) using the Laplace equation as the basis for static electric field analysis. Figure $5 \mathrm{a}$ and $\mathrm{b}$ illustrate the electric field magnitudes when the gap between the CAT harvester and PTFE is $2 \mathrm{~cm}$ and $2 \mathrm{~mm}$, respectively. As the gap decreases, the electric field is strengthened which indicates that the accumulated charges in PTFE are affecting the CAT harvester with a PDMS coating. When the PTFE sheet was brought into close proximity of the CAT harvester, the decreasing distance resulted in more induced negative charges accumulating in the core of the CAT harvester because the enhanced electric field attracts more positive charges on the outer shell (PDMS) of the thread. In this manner, free electrons flow from the PTFE sheet to the CAT harvester, and a negative current is produced. It is necessary to note that the rubbing mode had more charge accumulation on PTFE than the tapping mode, because more electrostatic charges are naturally produced due to the friction and increased contact area between the cotton textile and PTFE sheet. When there is contact between the PTFE sheet and CAT, most of the charges recombine rapidly and disappear. However, when the materials are separated, the CAT recovers its electrostatic charging state and small amounts of instantaneous positive current are produced. The asymmetric alternating output peaks through the load can be attributed to the electrostatic charging phenomenon a

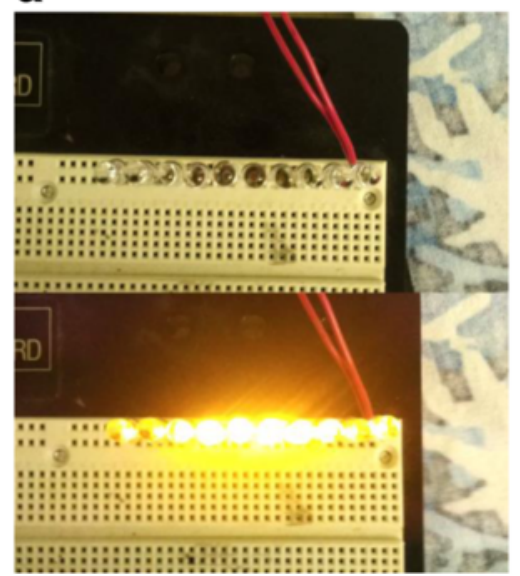

b

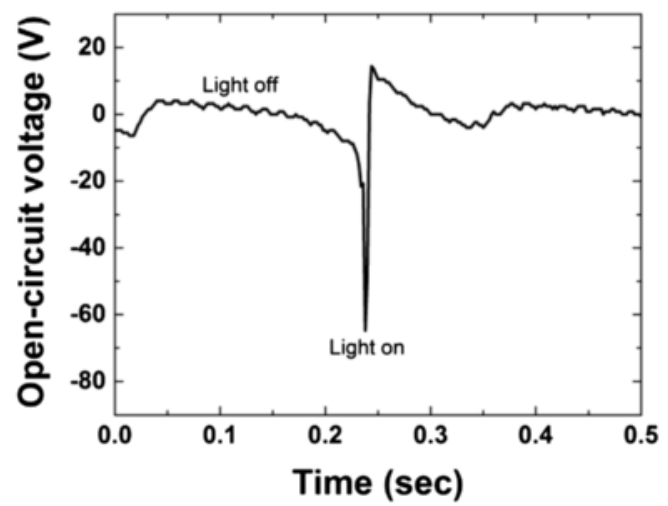

Figure 4 Produced power from CAT harvesters. (a) Photograph of flashing 10 LEDs connected with the cotton CAT harvester, powered by electrostatic charges and (b) time-dependent open-circuit voltage output. 

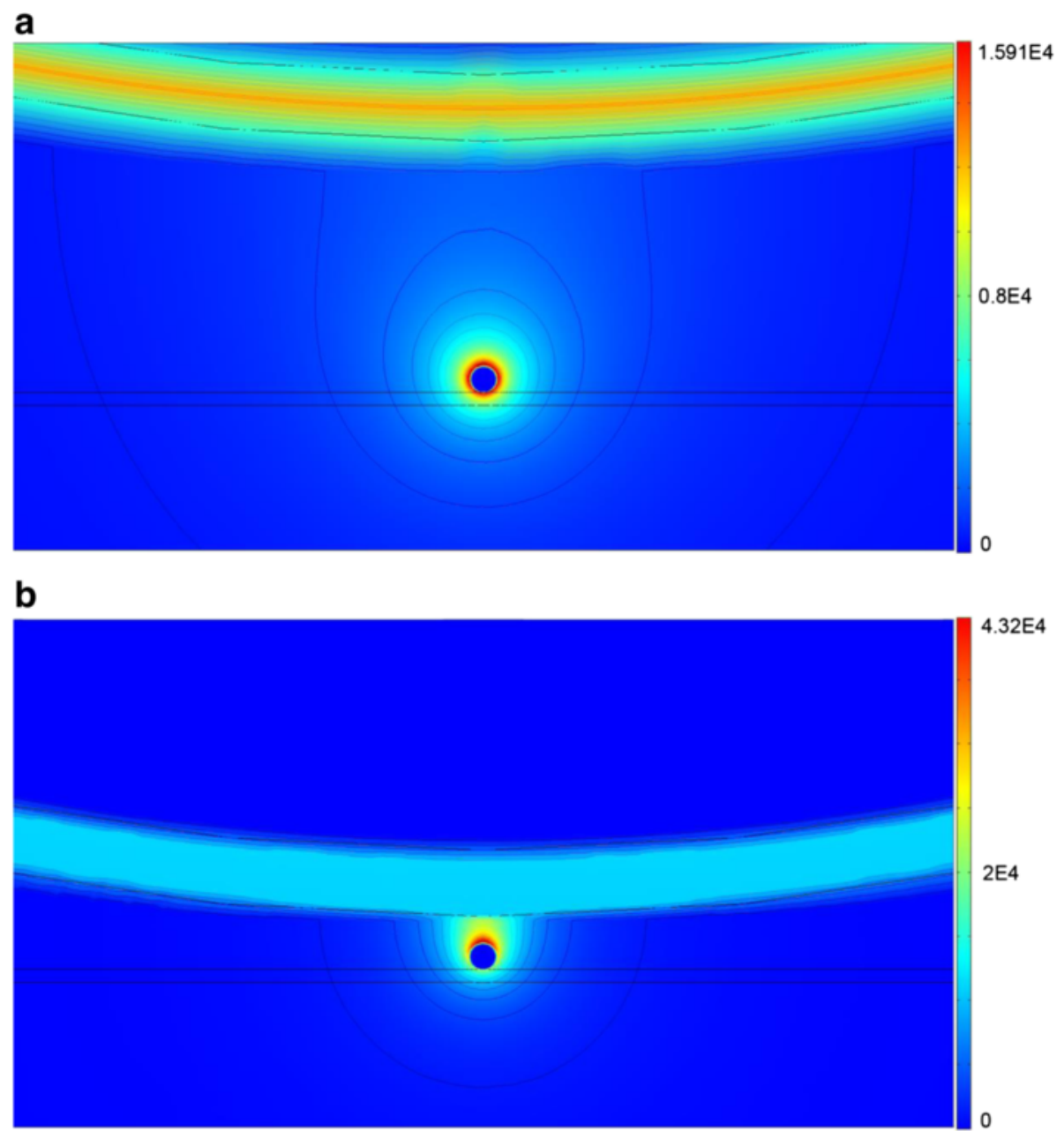

Figure 5 Simulated electric field properties between a CAT harvester and a PTFE sheet. Electric field between the CAT harvester (circled dot) and the PTFE sheet (curved line) when the gaps between them with a potential of $-60.9 \mathrm{~V}$ are (a) $2 \mathrm{~cm}$ and (b) $2 \mathrm{~mm}$, respectively. Unit is $V \mathrm{~m}^{-1}$.

when the CAT and PTFE sheet make repeated contact and separation with each other.

\section{Conclusion}

In this paper, we have successfully demonstrated a newly developed electrostatic generator with carbonactivated threads, easily fabricated using a simple and cost-effective coating process. The thread-based power harvesters exhibit excellent high output performance when the PTFE sheet comes into contact with the normal cotton textile stitched with CAT. The rubbing mode is represented by much higher output values than the tapping mode due to the increased collection of electrostatic charges in the PTFE sheet by increasing contact area between PTFE and the cotton textile. The collected charges in the PTFE sheet can induce charges in the core of the CAT harvester through the insulating silicone outer shell. The produced power turned on 10 LEDs, corresponding to the rubbing of PTFE on the cotton textile stitched with CAT. The CAT harvester has many possible novel applications in collecting and using mechanical energy that is otherwise wasted during everyday movements.

\section{Competing interests}

The authors declare that they have no competing interests.

\section{Authors contributions}

BK and BB participated in experiments and helped to draft the manuscript. $\mathrm{BK}, \mathrm{BB}$ and JK analysed the data, discussed the results. JK conceived and supervised this study. All authors read and approved the final manuscript.

Received: 4 December 2014 Accepted: 24 February 2015

Published online: 28 April 2015

\section{References}

1. Tao X (2005) Wearable Electronics and Photonics. CRC Press, Boca Raton, FL, USA

2. Wagner S, Bonderover E, Jordan WB, Sturm JC (2002) Electrotextiles: concepts and challenges. Int J Hi Spe Elec Syst 12:391-399

3. Tang SLP (2007) Recent developments in flexible wearable electronics for monitoring applications. Trans Inst Meas Contr 29:283-300 
4. Cherenack K, Zysset C, Kinkeldei T, Munzenrieder N, Troster G (2010) Woven electronic fibers with sensing and display functions for smart textiles. Adv Mater 45:5178-5182

5. Son D, Lee J, Qiao S, Ghaffari R, Kim J, Lee JE, Song C, Kim SJ, Lee DJ, Jun SW, Yang S, Park M, Shin J, Do K, Lee M, Kang K, Hwang CS, Lu N, Hyeon T, Kim DH (2014) Multifunctional wearable devices for diagnosis and therapy of movement disorders. Nature Nanotechnol 9:397-404

6. Rojas JP, Servilla GAT, Ghoneim MT, Inayat SB, Ahmed SM, Hussain AM, Hussain M (2014) Transformational silicon electronics. ACS Nano 8:1468-1474

7. Katragadda RB, Xu Y (2008) A novel intelligent textile technology based on silicon flexible skins. Sensors Actuators A 143:169-174

8. Marculescu D, Marculescu R, Zamora NH, Stanley-Marbell P, Khosla PK, Park S, Jayaraman S, Jung S, Lauterbach C, Wever W, Kirstein T, Cottet D, Grzyb J, Tröster G, Jones M, Martin T, Nakad Z (2003) Electronic textiles: a platform for pervasive computing. Proc IEEE 91:1995-2018

9. Lee YH, Kim JS, Noh J, Lee I, Kim HJ, Choi S, Seo J, Jeon S, Kim TS, Lee JY, Choi JW (2013) Wearable textile battery rechargeable by solar energy. Nano Lett 13:5753-5761

10. Bonfiglio A, De Rossi D (2011) Wearable monitoring systems. Springer, New York, USA

11. Wacharasindhu T, Kwon JW (2008) A micromachined energy harvester from a keyboard using combined electromagnetic and piezoelectric conversion. J Micromech Microeng 18:104016

12. Mattana G, Cosseddu P, Fraboni B, Malliaras GG, Hinestroza JP, Bonfiglio A (2011) Organic electronics on natural cotton fibres. Org Electron 12:2033-2039

13. Shim BS, Chen W, Doty C, Xu C, Kotov NA (2008) Smart electronic yarns and wearable fabrics for human biomonitoring made by carbon nanotube coating with polyelectrolytes. Nano Lett 8:4151-4157

14. Wei D, Cotton D, Ryhänen T (2012) All-solid-state textile batteries made from nano-emulsion conducting polymer ink for wearable electronics. Nanomater 2:268-274

15. Pasta M, La Mantia F, Hu L, Deshazer HD, Cui Y (2010) Aqueous supercapacitors on conductive cotton. Nano Res 3:452-458

16. Liu X, Chang H, Li Y, Huck WTS, Zheng Z (2010) Polyelectrolyte-bridged metal/cotton hierarchical structures for highly durable conductive yarns. ACS Appl Mater Inter 2:529-535

17. Wistrand I, Lingstrom T, Wagberg $L$ (2007) Preparation of electrically conducting cellulose fibres utilizing polyelectrolyte multilayers of poly(3,4-ethylenedioxythiophene):poly(styrene sulphonate) and poly(allyl amine). Eur Polym J 43:4075-4091

18. Bhadani SN, Kumari M, Sen Gupta SK, Sahu GC (1997) Preparation of conducting fibers via the electrochemical polymerization of pyrrole. J Appl Pol Sci 64:1073-1077

19. Knittel D, Schollmeyer E (2009) Electrically high-conductive textiles. Synth Met 159:1433-1437

20. Varesano A, Aluigi A, Florio L, Fabris R (2009) Multifunctional cotton fabrics. Synth Met 159:1082-1089

21. Ding Y, Invernale MA, Sotzing GA (2010) Conductivity trends of PEDOT-PSS impregnated fabric and the effect of conductivity on electrochromic textile. ACS Appl Mater Inter 2:1588-1593

22. Liu L, Oxenham W, Seyam AFM (2013) Contact electrification of polymeric surfaces. Ind J Fiber Text Res 38:265-269

23. Lam CW, James JT, McCluskey R, Arepalli S, Hunter RL (2006) A review of carbon nanotube toxicity and assessment of potential occupational and environmental health risks. Crit Rev Toxicol 36:189-217

24. Mardiguian M (2009) Electrostatic discharge: understand, simulate, and fix ESD problems. Wiley, Hoboken, NJ, USA

25. Gallot-Lavallée O (2013) Dielectric materials and electrostatics. Wiley, Hoboken, NJ, USA

\section{Submit your manuscript to a SpringerOpen ${ }^{\circ}$ journal and benefit from:}

- Convenient online submission

- Rigorous peer review

- Immediate publication on acceptance

- Open access: articles freely available online

- High visibility within the field

- Retaining the copyright to your article

Submit your next manuscript at springeropen.com 